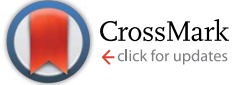

Cite this: RSC Adv., 2016, 6, 29899

Received 25th January 2016

Accepted 14th March 2016

DOI: $10.1039 / c 6 r a 02208 a$

www.rsc.org/advances

\section{Novel 3D lightweight carbon foam as an effective adsorbent for arsenic(v) removal from contaminated water}

\author{
Pinki Rani Agrawal, ${ }^{\text {ac }}$ Rajeev Kumar, ${ }^{a}$ Himani Uppal, ${ }^{\text {bc }}$ Nahar Singh, ${ }^{b}$ Saroj Kumari ${ }^{a}$ \\ and Sanjay R. Dhakate*a
}

In the present work, an efficient system for removal of pentavalent arsenic $(\mathrm{As}(\mathrm{V}))$ from water has been developed using a novel three-dimensional (3D) lightweight carbon foam. The carbon foam was synthesized from phenolic resin by a sacrificial template technique followed by stabilisation and carbonisation. The carbon foam was characterized by X-ray diffraction (XRD) for phase identification and energy dispersive spectroscopy (EDS) for compositional analysis. This same carbon foam has been utilized for the removal of $\mathrm{As}(\mathrm{V})$, and remaining concentrations were determined using an atomic absorption spectrophotometer-hydride generator (AAS-HG) at varying adsorption parameters, viz. time, $\mathrm{pH}$ and adsorbate dose. The adsorption data is best fitted to a Langmuir isotherm and suggests monolayer adsorption over a homogenous surface. The adsorption capacity of carbon foam is $38.4 \mu \mathrm{g}$ $\mathrm{g}^{-1}$ and the \% of arsenic removal is $99.1 \%$, which is very high as compared to other low density carbon materials. The carbon foams efficiently adsorbed As(v) and purify water below the prescribed limits of the world health organization (WHO) and the United States-environmental protection agency (US-EPA).

\section{Introduction}

The natural as well as anthropogenic contamination of toxic metals (mercury, cadmium, lead, arsenic, chromium) in the environment as per the U.S. Environmental Protection Agency (US-EPA) are of major concern because of their toxicity, bioaccumulating tendency, and threat to human life and the environment. ${ }^{1-4}$ Arsenic is one of the highly poisonous threats to the health of humans and ecological balance. ${ }^{5}$ Widespread arsenic contamination in groundwater has led to a massive epidemic in Asia and America, especially in India, Bangladesh, Vietnam, Cambodia, Thailand, southwest USA, Canada, Chile etc. Thus, the remediation of arsenic pollution has attracted worldwide attention. ${ }^{6,7}$

Arsenic concentration in various water bodies is increasing day by day due to several reasons like use of arsenical pesticides, mineral dissolution, mine drainage, disposal of fly ash, and geothermal discharge. According to the European Commission, WHO and US-EPA, the acceptable limit of arsenic in drinking

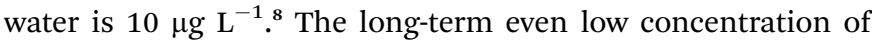
$\mathrm{As}(\mathrm{v})$ in drinking water disturbs the normal functioning of

${ }^{a}$ Physics \& Engineering of Carbon, Division of Material Physics and Engineering, CSIR-National Physical Laboratory, Dr. K.S. Krishnan Marg, New Delhi-110012, India. E-mail: dhakate@nplindia.org; Tel: +91-11-45609388

${ }^{b}$ Analytical Chemistry Division, CSIR-National Physical Laboratory, Dr. K.S. Krishnan Marg, New Delhi-110012, India

${ }^{c}$ Academy of Scientific and Innovative Research (AcSIR), India nervous and cardiovascular system and also increases the risk of cancer of skin, kidney, liver, and prostate.,

Several technologies reported in the literature for $\mathrm{As}(\mathrm{v})$ removal are precipitation, nanofiltration, reverse osmosis, electrodialysis, adsorption, ion exchange, solvent extraction, and bioremediation. ${ }^{\mathbf{1 1 - 1 6}}$ Most of these techniques are wellestablished and have their merits and inherent limitations such as the generation of toxic waste, low as removal efficiencies, and high cost. ${ }^{17}$ Among these techniques, adsorption has been recognized to be an efficient technique for $\mathrm{As}(\mathrm{v})$ removal. Besides these several materials like lanthanum, iron compounds, mineral oxides, and biological materials ${ }^{17,18}$ have been studied for As removal. The use of polymeric resins, activated carbon, ${ }^{19}$ activated alumina, iron-coated sand, ${ }^{20}$ hydrous ferric oxide, ${ }^{21}$ natural ores and metal modified adsorbents have generated much interest for better performance. ${ }^{22,23}$ Carbon materials like activated carbon, carbon fibers, carbon nanotubes (CNTs) and graphene have been studied for the removal of arsenic from ground water. Activated carbon and iron doped activated carbon have been developed for removing the arsenic from contaminated water due to selective affinity. ${ }^{24,25}$ Graphene and carbon nanotubes (CNT) also act as good adsorbent for arsenic because it possesses fibrous shape with high aspect ratio, large surface area and well developed mesopores. ${ }^{26,27} \mathrm{Liu}$ et al. demonstrated $\mathrm{TiO}_{2}$ coated carbon nanotube for removal of arsenic from contaminated water. ${ }^{28}$ Vadahanambi et al. and Mitra et al. has also developed multiwalled carbon nanotube 
(MWCNT) coated with $\mathrm{Fe}_{3} \mathrm{O}_{4}$ for removing even trace amount of arsenic to meet drinking water standards..$^{29,30}$

Porous materials are good candidates for adsorption of heavy metals because of facile diffusion of reactants and products through the pores, regular and tunable pore size with uniform pore structure, and good physiochemical stability as well as their large surface area and pore volume. ${ }^{31-33}$ It is known that porous carbon materials, which are thermally stable, chemically inert and low cost, show better adsorption property for heavy metals. Furthermore, Burke et al. ${ }^{34}$ and Lee et al. ${ }^{35}$ reported that mesoporous carbon foam have been used for the removal of copper and lead. Though significance progress has been made for the removal of heavy metals from water. However, nobody has reported yet the uptake proper mechanism and pathways for the removal of arsenic from water using carbon foam.

In view of above, we have fabricated 3D lightweight porous carbon foam of large and uniform pore size for the removal of As(v). The proposed fabricated carbon foam have interconnected pores having large surface area, large pore volume and provides several advantages over other types of mesoporous as well as carbon nanomaterials. The carbon foam was fabricated by dipping polyurethane foam template in phenol formaldehyde solution followed by oxidation at $300^{\circ} \mathrm{C}$ for $15 \mathrm{~h}$ in air atmosphere. Further carbonization was done at $1000^{\circ} \mathrm{C}$ in inert atmosphere.

\section{Experimental procedure}

\subsection{Chemicals and materials}

For the fabrication of carbon foam polyurethane foam (PU) as template was procured from S. G. \& Company, New Delhi-India. The chemicals for the fabrications, As(v) removal studies and potentiometric titration like phenol formaldehyde, acetone, sodium borohydride, hydrochloric acid, sodium hydroxide, potassium hydroxide, nitric acid, sodium salt of ethylene diamine tetra acetic acid, potassium nitrate etc. were procured from E. Merck India. All the chemicals used were of analytical grade. Double distilled water was used for the fabrication related work, while de-ionized water of 18.2 mega $\Omega$ resistivity (Millipore, Milli-Q element-USA) was used for absorption studies. The As(v) removal studies and calibration of AAS-HG was done using Merck Germany make traceable certified reference standard after appropriate dilutions. All the glassware used for fabrication and experimental studies were procured from Borosil India limited. The $\mathrm{pH}$ during experiments was adjusted using Orion make 3-star benchtop pH meter.

\subsection{Fabrication of carbon foam}

Carbon foam has been fabricated by the sacrificial template route by impregnating phenolic resin in the commercially available PU foams. ${ }^{36-39}$ The PU foams slabs (density, $0.030 \mathrm{~g}$ $\mathrm{cm}^{-3}$, cell size $0.45 \mathrm{~mm}$; cell number per unit length, 50 pores per inch) were used as a template. The templates were dipped into $35 \%$ of phenolic resin in organic solvent like acetone. Initially porous PU foam slabs (average dimensions: $30 \mathrm{~mm} \times$ $20 \mathrm{~mm} \times 10 \mathrm{~mm}$ ) have been cleaned with distilled water and dried in air at $100{ }^{\circ} \mathrm{C}$ for $6 \mathrm{~h}$. The dried foams were then dipped repeatedly 2-3 times into phenolic resin solution. The impregnated foams were dried in an oven at $100{ }^{\circ} \mathrm{C}$ for $12 \mathrm{~h}$ in order to evaporate organic solvent. The dried foams were then oxidised at $300{ }^{\circ} \mathrm{C}\left(@ 10^{\circ} \mathrm{C} \mathrm{h}^{-1}\right)$ in air atmosphere for one hour. This heat treatment process at $300{ }^{\circ} \mathrm{C}$ has been carried out for stabilization of the interconnected resin network by introducing crosslinks in the structure. Further the dried foams were carbonized at $1000{ }^{\circ} \mathrm{C}$ for 1 hour in inert atmosphere and resultant carbon foam having a bulk densities in the range of $0.25-0.35 \mathrm{~g}$ $\mathrm{cm}^{-3}$. The dried foams were then used for As(v) removal process. A schematic diagram from fabrication to $\mathrm{As}(\mathrm{v})$ adsorption has been given in Fig. 1 .

\subsection{Characterization}

The morphology of the carbon foams before and after removal of $\mathrm{As}(\mathrm{v})$ was observed by using scanning electron microscope [SEM (LEO 440)] from USA. FTIR studies were also carried out before and after removal of As(v) using thermo Nicolet model 380 procured from United Kingdom. The XPS spectra of carbon foam before and after removal of $\mathrm{As}(\mathrm{v})$ was obtained using a Multi Lab 2000 spectrometer (Thermo Electron Corporation, England) to investigate the elements composition and surface groups present on the surface of the carbon foam samples. Al $\mathrm{K} \alpha(1485.6 \mathrm{eV})$ was used as the X-ray source with a $14.9 \mathrm{keV}$ anode voltage, a $4.6 \mathrm{~A}$ filament current and a $20 \mathrm{~mA}$ emission current. The XPS spectra were obtained with $50 \mathrm{eV}$ pass energy and a $0.5 \mathrm{eV}$ step size. Core level spectra were obtained at $20 \mathrm{eV}$ pass energy with a $0.05 \mathrm{eV}$ step size. The phase identification and crystallite size of pure foam and after As(v) adsorption were done using Rigaku powder X-ray diffractometer (model XRG $2 \mathrm{kw})$ using $\mathrm{Cu} \mathrm{K} \alpha$ radiation $(\lambda=1.54059 \AA)$. The As(v) removal studies were carried out using Analytic Jena Germany make AAS-HG, model vario-6 at optimized conditions.

\subsection{Point zero charge}

Point of zero charge (pzc) is the $\mathrm{pH}$ of a material at which the surface of the material becomes neutrally charged. $\mathrm{The}_{\mathrm{pH}}$ prc carbon foam has been confirmed using potentiometric titration. ${ }^{40}$ To determine $\mathrm{pH}_{\mathrm{pzc}}$, carbon foam was dipped in $25 \mathrm{~mL}$ solution of $0.03 \mathrm{M} \mathrm{KNO}_{3}$ solution and the solution was left overnight $(24 \mathrm{~h})$ under constant stirring for stabilizing the $\mathrm{pH}$. Further $0.1 \mathrm{~mL}$ solution of $1 \mathrm{M} \mathrm{KOH}$ was added into the solution of $\mathrm{KNO}_{3}$ and $\mathrm{pH}$ was recorded after each addition of $20 \mu \mathrm{L}$ solution of $0.1 \mathrm{M} \mathrm{HNO}_{3}$ using micropipette. Blank titration was also done in a similar way. The $\mathrm{pH}_{\mathrm{pzc}}$ of the carbon foam was determined from the curve of $\mathrm{pH}$ against acid consumed as presented in Fig. 2(a).

\subsection{Adsorption studies}

For the As(v) adsorption study, the stock solution of As(v) of desired strength was prepared after appropriate dilution in deionized water. The $\mathrm{pH}$ of the solution was adjusted by adding solution of $0.001 \mathrm{M} \mathrm{HCl}$ and $\mathrm{KOH}$. The carbon foam was dipped for 24 hours. The decanted solution was analyzed for left over concentration of $\mathrm{As}(\mathrm{v})$ using $3 \%$ sodium borohydride, $1.5 \%$ $\mathrm{NaOH}$, and $2 \% \mathrm{HCl}$ for arsenic hydride generation. Atomization 

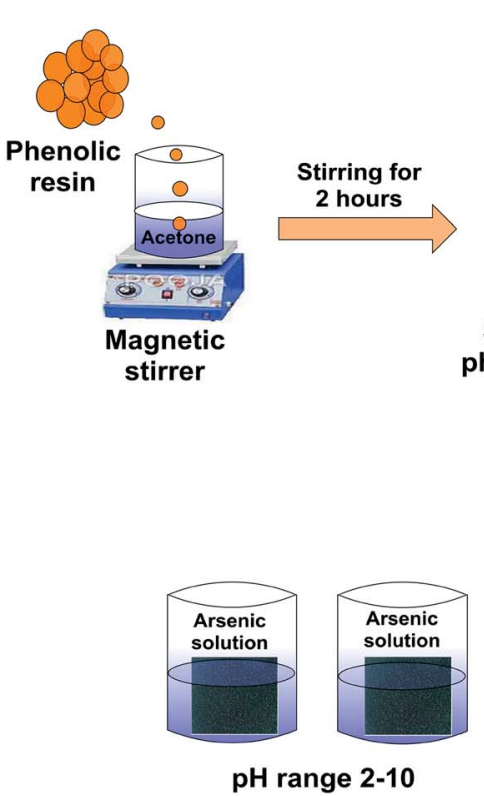
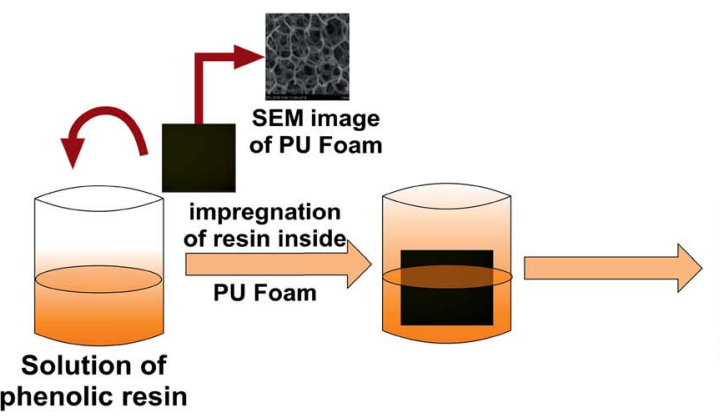

Impregnated

Foam

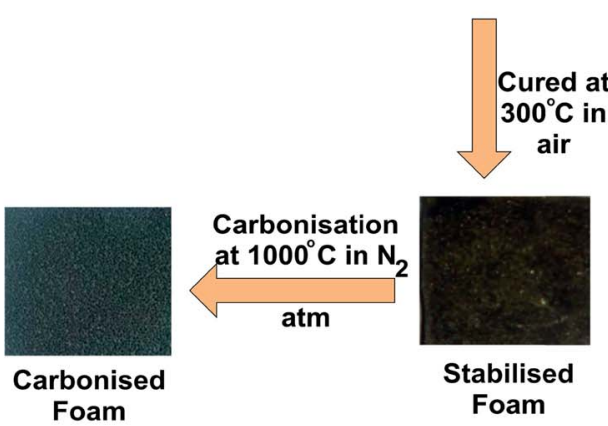

Fig. 1 Schematic diagram shows the fabrication process of carbon foam for the removal of $\mathrm{As}(\mathrm{v})$.
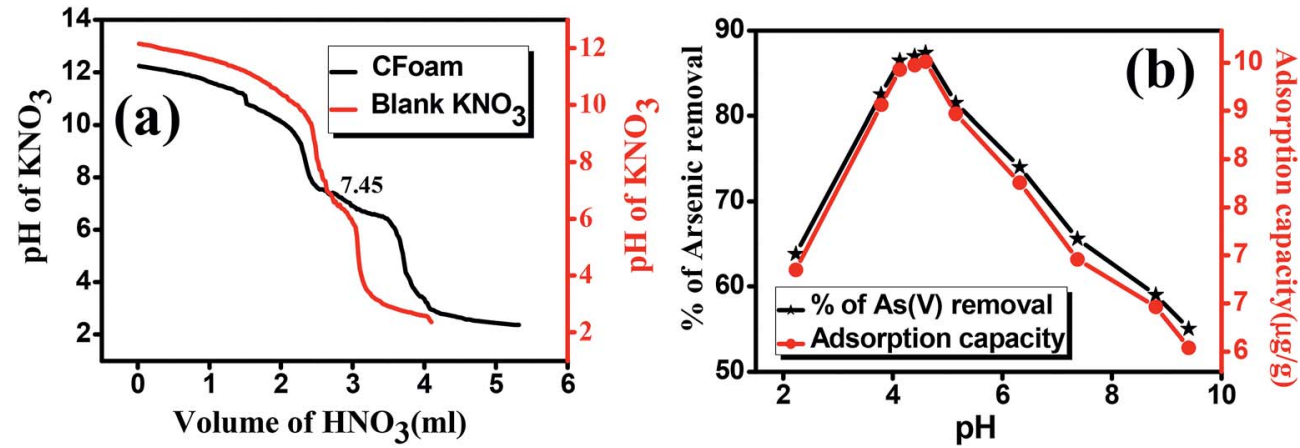

Fig. 2 (a) $\mathrm{pH}_{\mathrm{pzc}}$ and (b) effect of $\mathrm{pH}$ on arsenic(v) adsorption capacity.

of $\mathrm{As}(\mathrm{v})$ was carried out at $900{ }^{\circ} \mathrm{C}$ using electro thermal heating in the presence of argon gas with $36 \mathrm{~mL} \mathrm{~min}{ }^{-1}$ flow rate..$^{41}$ The adsorption capacity of carbon foam was calculated by using eqn (1) and (2)

$$
\begin{aligned}
& \text { Adsorption capacity }=\frac{\left(C_{\mathrm{i}}-C_{\mathrm{f}}\right)}{w} \times V \\
& \% \text { of arsenic removal }=\frac{C_{\mathrm{i}}-C_{\mathrm{f}}}{C_{\mathrm{i}}} \times 100
\end{aligned}
$$

where $C_{\mathrm{i}}$ is initial concentration of arsenic(v) solution, $C_{\mathrm{f}}$ is the final concentration of $\operatorname{As}(\mathrm{v})$ remaining in the solution; $V$ is the volume of solution, $w$ is the weight of adsorbent $(\mathrm{g})$.

\section{Results and discussion}

\subsection{Effect of $\mathbf{p H}$}

The $\mathrm{pH}$ of the aqueous solution is the most important factor for $\operatorname{As}(\mathrm{v})$ removal. The relationship between the $\mathrm{pH}$ and $\mathrm{pH}_{\mathrm{pzc}}$ of a solution has a significant effect on adsorption at the liquidsolid interface. As(v) species is present in water with three forms of which the acid base dissociation constant $\left(\mathrm{p} K_{a}\right)$ values are 2.2, 7.0 and 11.5 respectively. ${ }^{42} \mathrm{H}_{2} \mathrm{AsO}_{4}{ }^{-}$and $\mathrm{HAsO}_{4}{ }^{2-}$ are the main species which is found in natural water with $\mathrm{pH}$ range 5-8. For the optimization of $\mathrm{pH}$ several sets of solution were prepared by varying $\mathrm{pH}$ from 2 to 10 and in these solutions, carbon foams were dipped in these solutions and kept for 24 hours. The decanted solutions were analysed by AAS-HG for remaining concentration of $\mathrm{As}(\mathrm{v})$. The \% removal of $\mathrm{As}(\mathrm{v}) v s . \mathrm{pH}$ has been presented in Fig. 2(b). From the figure it has been observed that maximum adsorption occurred between 4 to 5 $\mathrm{pH}$, whereas on increasing $\mathrm{pH}$ above 5 , there is a gradual decrease adsorption. The distribution profile was constructed as a function of solution $\mathrm{pH}$ based on the following three equilibrium and their respective stability constants.

$$
\mathrm{H}_{3} \mathrm{AsO}_{4} \rightarrow \mathrm{H}_{2} \mathrm{AsO}_{4}^{-}+\mathrm{H}^{+}\left(\mathrm{p} K_{1}=2.3\right)
$$




$$
\begin{aligned}
& \mathrm{H}_{2} \mathrm{AsO}_{4}{ }^{-} \rightarrow \mathrm{HAsO}_{4}{ }^{2-}+\mathrm{H}^{+}\left(\mathrm{p} K_{2}=6.7\right) \\
& \mathrm{HAsO}_{4}{ }^{2-} \rightarrow \mathrm{AsO}_{4}{ }^{3-}+\mathrm{H}^{+}\left(\mathrm{p} K_{3}=11.6\right)
\end{aligned}
$$

The $\mathrm{pH}_{\mathrm{pzc}}$ of the carbon foam was observed to be 7.45 , whereas maximum adsorption occurred between 4 and $5 \mathrm{pH}$ ranges, which denote that the surface of the adsorbent is positively charged. The surface of the adsorbate is negatively charged $\left(\mathrm{H}_{2} \mathrm{AsO}_{4}{ }^{-}\right)$, while surface of adsorbent is positively charged and would be involved in protonation of $-\mathrm{OH}$ group. The positive surface of adsorbent (carbon foam) attracts the negative surface of adsorbate $\left(\mathrm{H}_{2} \mathrm{AsO}_{4}{ }^{-}\right)$because of electrostatic interaction. The schematic diagram of possible chemical interaction is given in Fig. 3.

\subsection{Structural and morphological analysis}

The XPS is an excellent tool to identify the functional groups present on the surface of the material. The XPS spectra of carbon foam before and after As(v) adsorption were taken as given in Fig. 4(a-d). It consist of carbon C1s and oxygen O1s spectra, which is due to the electron transition from carbonoxygen atoms of different atomic configuration and their shape depends upon atomic densities. The evaluation of bonding content consists of spectra background subtraction, followed by fitting of Gaussian-Lorentzian asymmetric functions to the measured spectra, selecting the relevant binding energy values from literature. ${ }^{22}$ In both the cases, asymmetric peaks were observed centred at different binding energies with long tail extended to the higher energy region. In both the cases, (carbon foam before and after arsenic adsorption), the deconvolution of C1s spectra is split into four peaks as shown in Fig. 4(a) and (c). The first (C1s A) peak was observed at $284.5 \mathrm{eV}$ of carbon (C-C) in graphitic type, second peak (C1s B) was found at $286.0 \mathrm{eV}$ of carbon singly bound to oxygen $(\mathrm{C}-\mathrm{O})$ in phenols and ethers, third peak (C1s C) was found at $286.6 \mathrm{eV}$ of carbon doubly

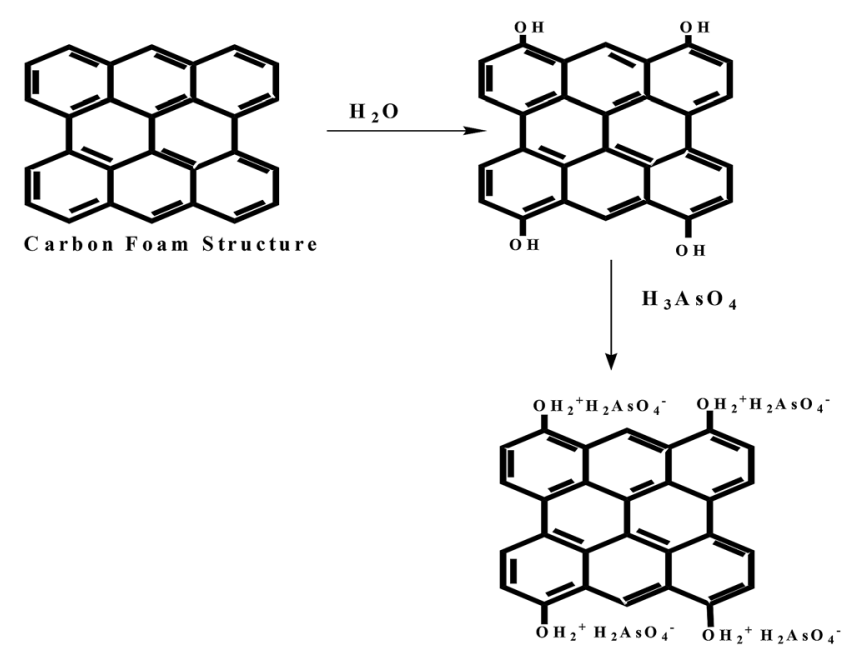

Fig. 3 Schematic diagram of chemical interaction between carbon foam and $A s(v)$. bound to oxygen $(\mathrm{C}=\mathrm{O})$ in ketones and quinones, and fourth peak (C1s D) at 289.2 of carbon bound to two oxygen (-COO) in carboxyl, carboxylic anhydrides and ester. Moreover, deconvolution of the O1s spectrum of both carbon foams split into two peaks (Fig. 4(b) and (d)), first oxygen doubly bound to carbon $(\mathrm{O}=\mathrm{C})$ at $533.2 \mathrm{eV}$ in the form of quinones, ketones and aldehydes and second oxygen single bound to carbon $(\mathrm{O}-\mathrm{C})$ at 536.6 $\mathrm{eV}$ in the form of ethers and phenols. However, after adsorption of As(v), the carbon and oxygen peak area is gradually increase as show in Fig. 4(c) and (d). Fig. 4(e) shows the XPS spectra of As(v) in carbon foam after adsorption. The peaks at 43 and 45.26 $\mathrm{eV}$ are assigned $\mathrm{As}$ and $\mathrm{As}_{2} \mathrm{O}_{5}$ respectively. ${ }^{\mathbf{4 3 , 4 4}}$

XRD spectra of carbon foam before and after As(v) adsorption are shown in Fig. 5(a) and (b) respectively. Two broad diffraction peaks at $24.9^{\circ}$ and $43.1^{\circ}$ are shown in Fig. 5(a) which correspond to the amorphous nature of carbon of (002) and (100) lattice plane, respectively, which is due to the turbostatic nature of phenolic resin at $1000{ }^{\circ} \mathrm{C}$. This finding is due to the formation of glassy carbon structures from which is derived from thermosetting phenolic resin polymer. The peak at $2 \theta=$ $24.9^{\circ}$ corresponds to (002) plane of carbon materials. It is seen that the interlayer spacing $\left(d_{002}\right)$ of pristine carbon foam is $0.3509 \mathrm{~nm}$. However, after adsorption of As(v) onto the carbon foam, the peak at $2 \theta=24.9^{\circ}$ is shifted to $25.1^{\circ}$ as presented in Fig. 5(b). The shifting and increases in peak intensity confirms the presence of As(v) adsorption over the carbon foam.

The FTIR spectra of pristine carbon foam and carbon foam after $\mathrm{As}(\mathrm{v})$ adsorption recorded by varying wave number in the range of 4000-500 $\mathrm{cm}^{-1}$ are shown in Fig. 5(c) and (d). In both the samples, it can be seen that there are strong absorption peaks in the range of $3400-3700 \mathrm{~cm}^{-1}$. These are due to $-\mathrm{OH}$ stretching vibrations; and indicate the presence of high content of hydroxyl groups present on the surface of carbon foam.

The absorption peaks at 3040 and $3042 \mathrm{~cm}^{-1}$ indicate the presence of $\mathrm{sp}^{2}$ carbon $(\mathrm{C}=\mathrm{C})$. After $\mathrm{As}(\mathrm{v})$ adsorption by carbon foam (Fig. 5(d)), three new peaks are observed between the wave number of $800-1600 \mathrm{~cm}^{-1}$, the peaks in this range are due to $\mathrm{As}(\mathrm{v})$ adsorption on the surface of carbon foam as confirmed by XRD. The peak at $1450 \mathrm{~cm}^{-1}$ indicates the symmetric and asymmetric stretching of $\mathrm{COO}^{-}$group and peak at $1060 \mathrm{~cm}^{-1}$ is due to $\mathrm{C}=\mathrm{O}$ stretching of the $\mathrm{COO}^{-}$group and peak at $870 \mathrm{~cm}^{-1}$ is due to the $-\mathrm{OH}$ bonding.

SEM images of pristine carbon foam as well as after adsorption of As(v) are depicted in Fig. 6(a) and (b). As seen in Fig. 6(a), the carbon foam exhibits fairly surface and uniform pore size in the range $200-300 \mu \mathrm{m}$ with a narrow ligaments. Also, virtually all cells are open and connected to several neighbouring cells. An XRD result shows that carbon foam having turbostatic structures (higher interlayer spacing) which correspond to the amorphous nature of carbon. However, when this carbon foam was used to remove $\mathrm{As}(\mathrm{v})$ from water there is some chemical reaction are occurred and form $\mathrm{C}-\mathrm{H}_{2} \mathrm{AsO}_{4}{ }^{-}$. Due to this chemical interaction and acidic nature of $\mathrm{H}_{2} \mathrm{AsO}_{4}{ }^{-}$, carbon foam ligaments gets deformatted and wider as shown in Fig. 6(b), moreover, the surface of carbon foam is become coarser by deposition of As(v). 

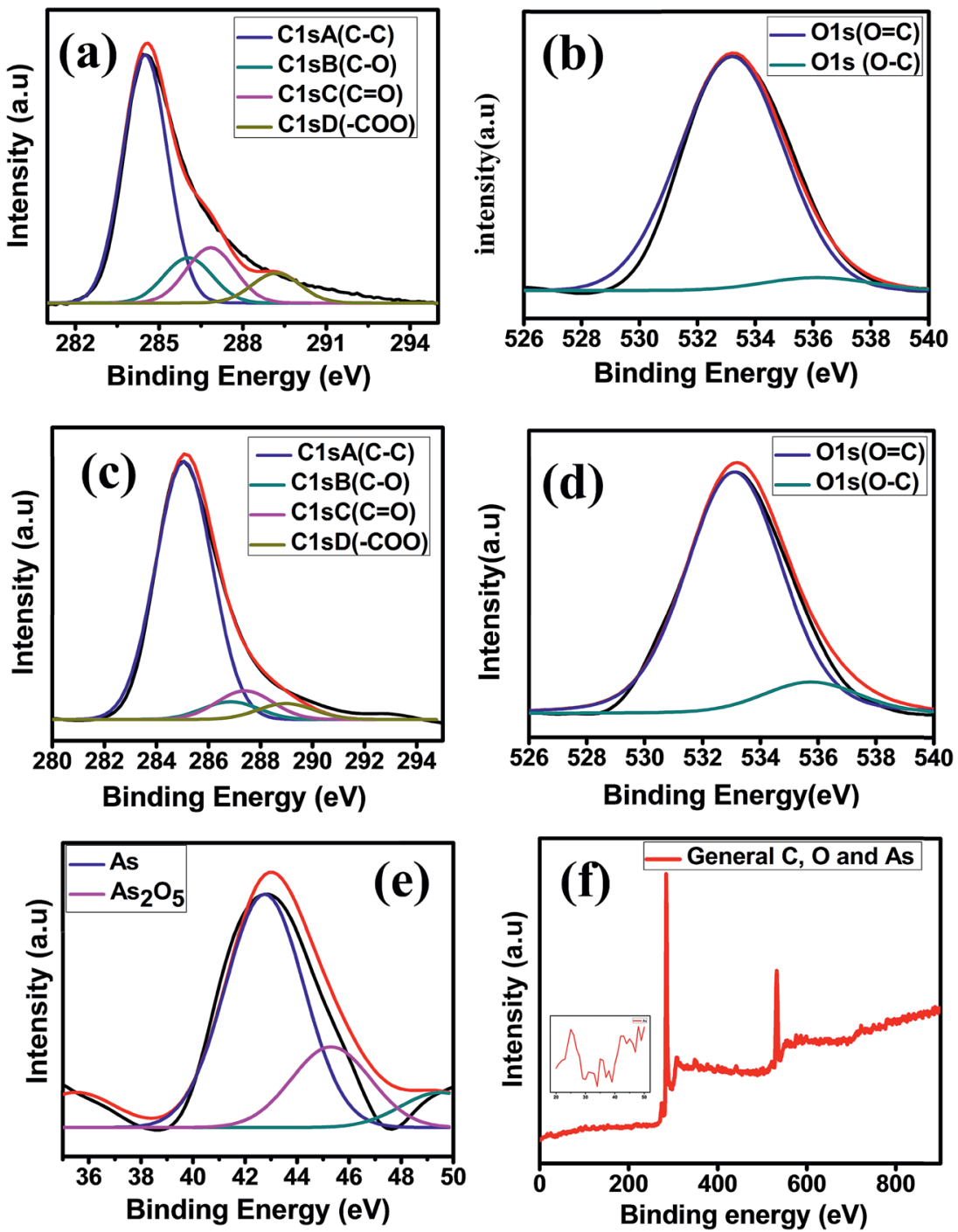

Fig. 4 XPS spectra of carbon foam before As( $(v)$ adsorption ( $a$ and $b$ ) and $(c-f)$ after $A s(v)$ adsorption.

\subsection{Kinetic study}

Kinetic study is one of the most important characteristics that define the efficiency of adsorption. The experiment has been brought off with $1 \mathrm{mg} \mathrm{L}^{-1}$ concentration of As(v) at optimized parameters. Fig. 7 represents the adsorption efficiency of carbon foams with respect to time. It has been observed that maximum adsorption occurred in 6 hours. The proposed material effectively removed As(v) below prescribed limits of WHO. Fig. 7(a-d) represents percent removal, adsorption capacity, pseudo second order, and first order kinetics respectively. The pseudo second order kinetics has been given in eqn (6) and (7).

$$
\frac{t}{q_{t}}=\frac{1}{k_{2} q_{\mathrm{e}}^{2}}+\frac{t}{q_{\mathrm{e}}} \quad(\text { pseudo second order })
$$

In above equation, if time ' $t$ ' is zero, then the initial sorption rate ' $h$ ' will be calculated using eqn (7).

$$
h=k_{2} q_{\mathrm{e}}^{2}
$$

In above eqn (6) and (7), ' $q_{\mathrm{e}}$ ' and ' $q_{t}$ ' $\left(\mu \mathrm{g} \mathrm{g}^{-1}\right)$ are the adsorption capacity of carbon foam at equilibrium ' $\mathrm{e}$ ' and at time ' $t$ ' respectively, ' $h$ ' $\left(\mu \mathrm{g} \mathrm{g}^{-1} \mathrm{~min}^{-1}\right)$ represents the initial adsorption rate and ' $k_{2}$ ' $\left(\mathrm{g} \mu \mathrm{g}^{-1} \mathrm{~min}^{-1}\right)$ is the rate constant.

The pseudo first order kinetics (eqn (8)), represents the adsorption rates which depend either on the concentration of adsorbate or adsorbent.

$$
\ln \left(q_{\mathrm{e}}-q_{t}\right)=\ln q_{\mathrm{e}}-k_{1} t \text { (pseudo first order) }
$$

In eqn (8), ' $q$ e' and ' $q_{t}$ ' $\left(\mu \mathrm{g} \mathrm{g}^{-1}\right)$ are the adsorption capacity of carbon foam at equilibrium 'e' and at time ' $t$ ' respectively, ' $k_{1}$ ' is the rate constant $\left(\mathrm{min}^{-1}\right)$.

The adsorption kinetics experimental data was fitted to eqn (6) and (8) to study the adsorption behaviour of the carbon foam. This study suggests whether the material follow pseudo second or first order kinetics. Fig. 7(b) shows the adsorption capacity of carbon foam with respect to time. The adsorption capacity of the proposed carbon foam was found to be $10 \mu \mathrm{g}$ 

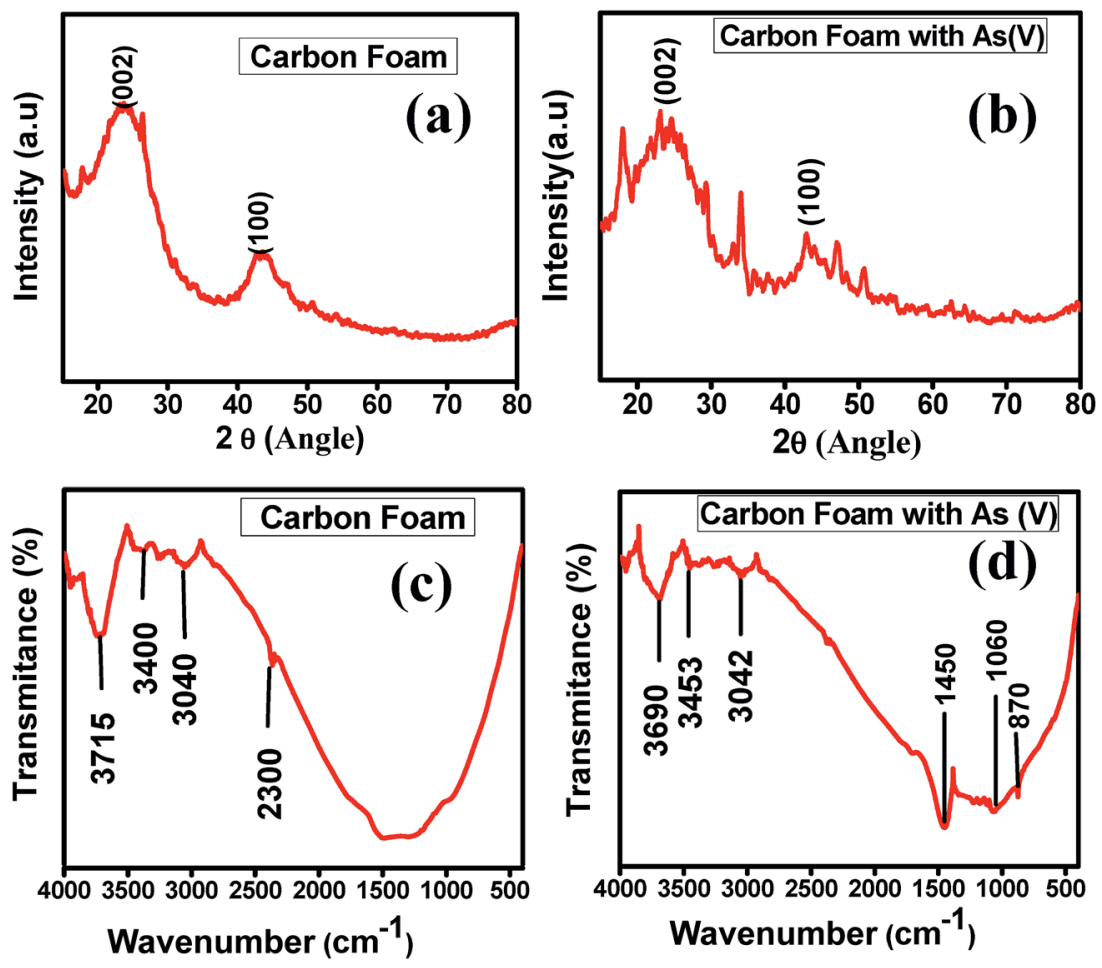

Fig. 5 (a) and (b) XRD spectra and (c) and (d) FTIR spectra of carbon foam before and after As(v) adsorption respectively.

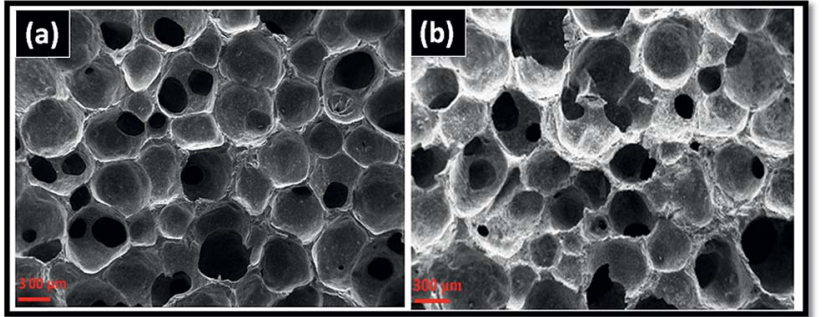

Fig. 6 SEM images of (a) pristine carbon foam, (b) after $A s(v)$ adsorption.

$\mathrm{g}^{-1}$. Fig. $7(\mathrm{c})$ explains the pseudo second order kinetics equation with respect to adsorption capacity ' $t / q_{t}$ ' $v s$. time ' $t$ '. The adsorption capacity ' $q$ ', adsorption rate ' $h$ ', rate constant ' $k$ ' and coefficient of determination ' $R$ ', was calculated by slope

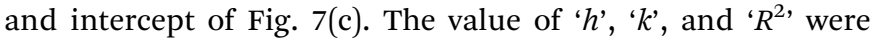

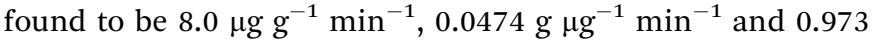
respectively. The adsorption capacity $\left(q_{\mathrm{e}}\right)$ was calculated from Fig. 7(c) and compare with the experimental data. It has been concluded that experimental adsorption capacity $\left(10 \mu \mathrm{g} \mathrm{g}^{-1}\right)$ and theoretical adsorption capacity $\left(13 \mu \mathrm{g} \mathrm{g}^{-1}\right)$ results are comparable. Fig. 7(d) represents the pseudo first order kinetic, and it has been observed that first order kinetics is not applicable for the proposed material. From the Fig. 7(d), the value of ' $R$ ' is found to 0.90 , which is less than pseudo second order kinetics (0.97). We can be concluded that the adsorption kinetics follows second order kinetic and the adsorption rate of $\operatorname{As}(\mathrm{v})$ depends on the concentration of adsorbate and adsorbent.

\subsection{Adsorption isotherm}

Adsorption isotherm describes the equilibrium relationship between solid and liquid interfaces and can be explained in the form of Langmuir, Freundlich, Temkin and Dubinin-Radushkevich (D-R) isotherms. ${ }^{45}$ In the proposed study we have used only Langmuir, Freundlich isotherm to understand the behaviour of adsorbent and adsorbate. Langmuir isotherm suggests that adsorption of the metal ions occurs on a homogeneous surface by monolayer without any interaction between adsorbent and adsorbate. It also describes numbers of specific active sites which interacts with adsorbate molecules. Whereas, Freundlich adsorption isotherm suggests heterogeneous nature of adsorbent surface and multilayers adsorption of the adsorbate onto the surface of adsorbent. ${ }^{46}$ The adsorption capacity of carbon foam for $\operatorname{As}(v)$ has been calculated using the equilibrium adsorption isotherm by varying the initial concentration of $\operatorname{As}(\mathrm{v})$ from 1 to $10 \mathrm{mg} \mathrm{L}^{-1}$ with fixed amount of adsorbent (approx. $1.8 \mathrm{~g}$ ). All the experiments were carried out in $25 \mathrm{~mL}$ of $\mathrm{As}(\mathrm{v})$ solutions. Initially the adsorption capacity of carbon foam increases, which gradually decreases on increasing concentration of As(v) due to exhaust of active sites present over the surface of carbon foam. The maximum adsorption capacity of carbon foam was observed at $3 \mathrm{mg} \mathrm{L}^{-1}$ concentration within 6 hours and shown in Fig. 8(a).

The adsorption capacity of fixed amount of carbon foam $v s$. remaining concentration of As(v) data were fitted using Langmuir isotherm. The adsorption capacity of carbon foam was calculated using eqn (9) as given below;

$$
\frac{C_{\mathrm{f}}}{q_{\mathrm{e}}}=\frac{1}{K_{\mathrm{L}} q_{\mathrm{m}}}+\frac{C_{\mathrm{f}}}{q_{\mathrm{m}}}
$$



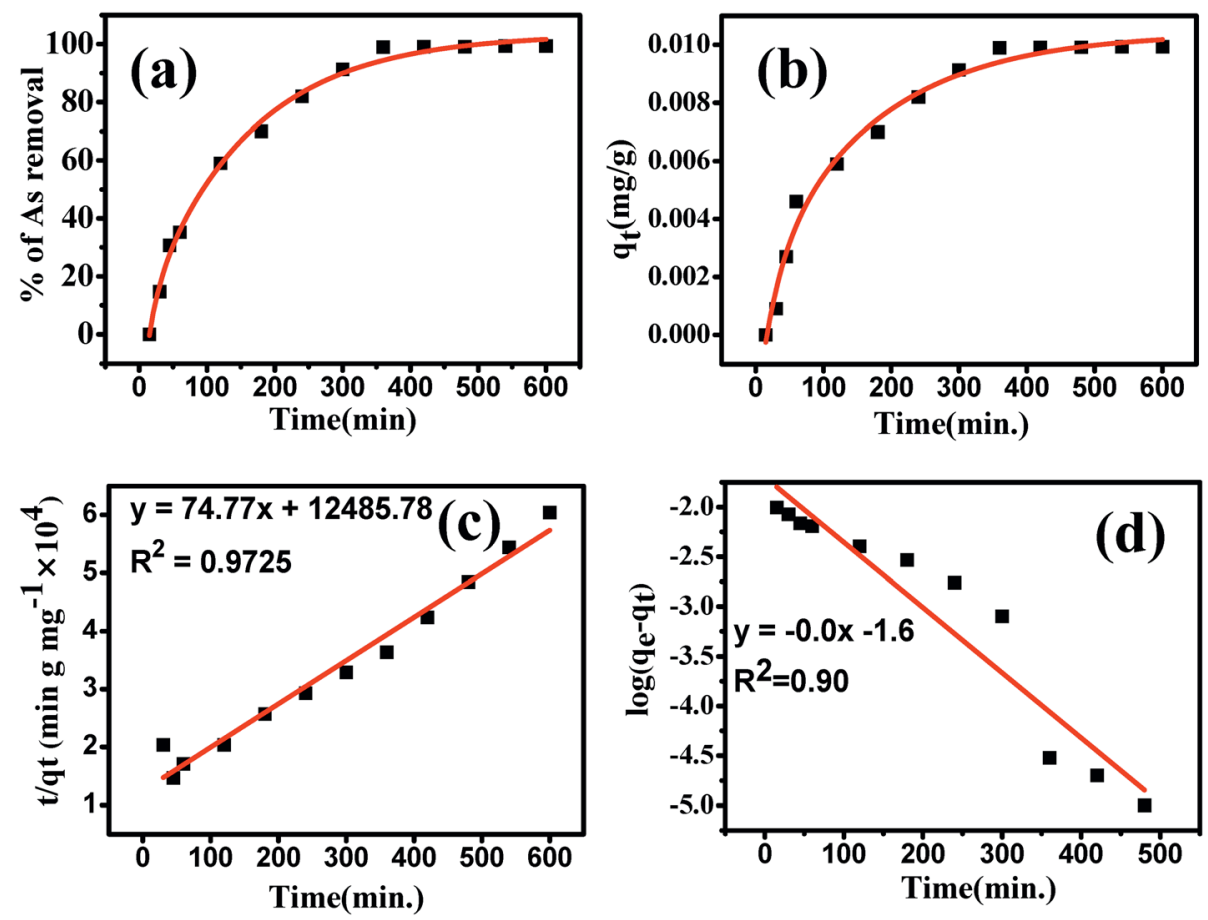

Fig. 7 Effect of time on (a) As(v) removal, (b) adsorption capacity $\left(q_{t}\right)$ of As(v), (c) pseudo second order kinetics and (d) pseudo first order kinetics.
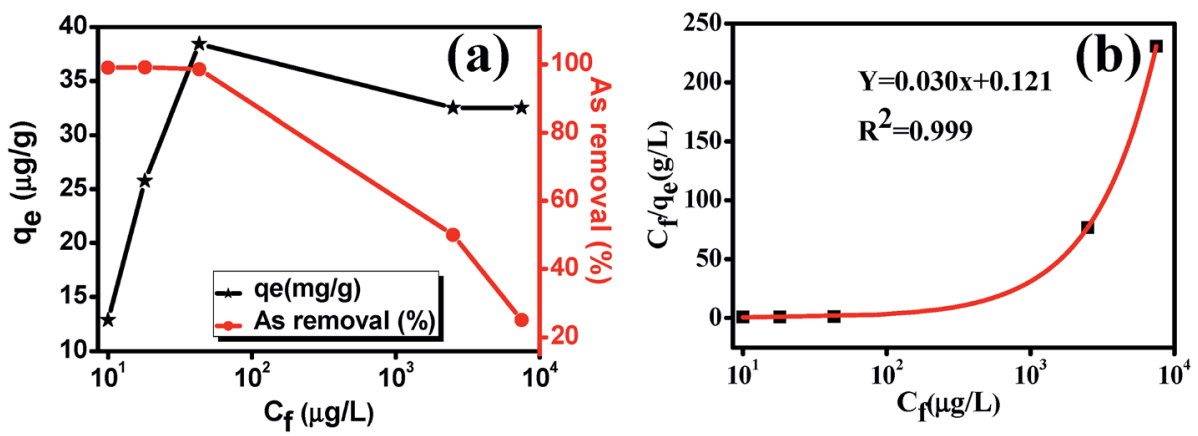

Fig. 8 (a) Effect of remaining concentration of $A s(v)$ on adsorption capacity of carbon foam, and (b) Langmuir adsorption isotherm.

where $C_{\mathrm{f}}\left(\mathrm{mg} \mathrm{L}^{-1}\right)$ is the remaining concentration of $\mathrm{As}(\mathrm{v}), q_{\mathrm{e}}(\mu \mathrm{g}$ $\left.\mathrm{g}^{-1}\right)$ is the adsorption capacity at equilibrium, $q_{\mathrm{m}}\left(\mu \mathrm{g} \mathrm{g}^{-1}\right)$ is the maximum adsorption capacity, $K_{\mathrm{L}}\left({\left.\mathrm{L} \mu \mathrm{g}^{-1}\right)}^{-1}\right.$ is the energy of reaction.

The value of $K_{\mathrm{L}}$ and $q_{\mathrm{m}}$ were calculated from linear plot of ' $C_{\mathrm{f}} / q_{\mathrm{e}}$ ' $v s$. ' $C_{\mathrm{f}}$ ' as shown in Fig. $8(\mathrm{~b})$. The value of $K_{\mathrm{L}}, q_{\mathrm{m}}$, and $R^{2}$ were found to be $0.248 \mathrm{~L} \mathrm{\mu g}^{-1}, 38.44 \mu \mathrm{g} \mathrm{g}{ }^{-1}$ and 0.999 respectively. The value of regression coefficient was found to be 0.999 , which follows Langmuir isotherm. On the basis of Langmuir isotherm, it can be concluded that there is a monolayer adsorption over carbon foam surface. The value of separation factor $\left(R_{\mathrm{L}}\right)$ was calculated using eqn (10) as given below;

$$
R_{\mathrm{L}}=\frac{1}{1+\left(K_{\mathrm{L}} C_{\mathrm{i}}\right)}
$$

In the above equation, $C_{\mathrm{i}}$ denotes initial concentration of arsenic solution, $K_{\mathrm{L}}$ is Langmuir constant. The separation factor $\left(R_{\mathrm{L}}\right)$ value describes the nature of adsorption as given below;

$$
\begin{gathered}
R_{\mathrm{L}}>1 \text { unfavourable, } \\
R_{\mathrm{L}}=0 \text { then linear, } \\
0<R_{\mathrm{L}}<1 \text { favourable, } \\
R_{\mathrm{L}}>0 \text { irreversible }
\end{gathered}
$$

On the basis of above assumptions, separation factor, ${ }^{47}$ the value of $R_{\mathrm{L}}$ was found less than 1, which suggest feasibility of the process and adsorption of $\mathrm{As}(\mathrm{v})$ over the surface of carbon foam is favourable. 


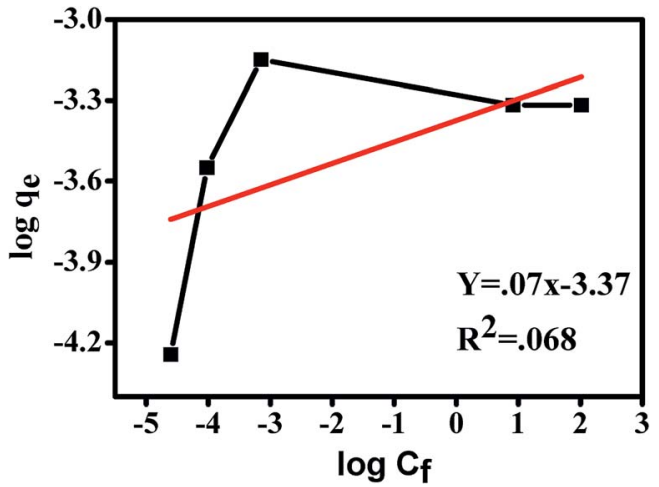

Fig. 9 Freundlich adsorption isotherm.

The Freundlich isotherm has also been studied to know the heterogeneous nature of carbon foam. The data has been fitted in Freundlich adsorption isotherm as given below

$$
\begin{gathered}
q_{\mathrm{e}}=K_{\mathrm{f}} C_{\mathrm{f}}^{1 / n} \\
\log q_{\mathrm{e}}=\log K_{\mathrm{f}}+1 / n \log C_{\mathrm{f}}
\end{gathered}
$$

where; ' $K_{\mathrm{f}}$ ' and ' $1 / n$ ' are Freundlich parameters which represent distribution coefficient $\left(\mathrm{L} \mathrm{g}^{-1}\right)$ and intensity of adsorption respectively. The regression coefficient value was obtained as 0.068 which is very less as a result the adsorption of arsenic is found homogeneous nature and does not follow Freundlich adsorption isotherm as show in Fig. 9.

\subsection{Reusability of carbon foam}

The reusability of carbon foam has been investigated after treating used carbon foam with $5 \%$ solution of EDTA and $\mathrm{HNO}_{3}$ solution. First the used carbon foam was sonicated in $5 \%$ solution of EDTA and $\mathrm{HNO}_{3}$ separately for one hour.

The decanted solutions were checked for leached concentration of $\mathrm{As}(\mathrm{v})$ by AAS-HG. It has been found that most of As(v) releases from the carbon foam surface. The same observations were further confirmed by SEM-EDX analysis as given in Fig. 10(a-d). The EDTA is a strong chelating agent and makes complexes with As(v). In the same way As(v) probably forms arsenic acid after treating with $\mathrm{HNO}_{3}$ solution as given in chemical eqn (13).

$$
5 \mathrm{HNO}_{3}+\mathrm{As} \rightarrow \mathrm{H}_{3} \mathrm{AsO}_{4}+5 \mathrm{NO}_{2}+\mathrm{H}_{2} \mathrm{O}
$$
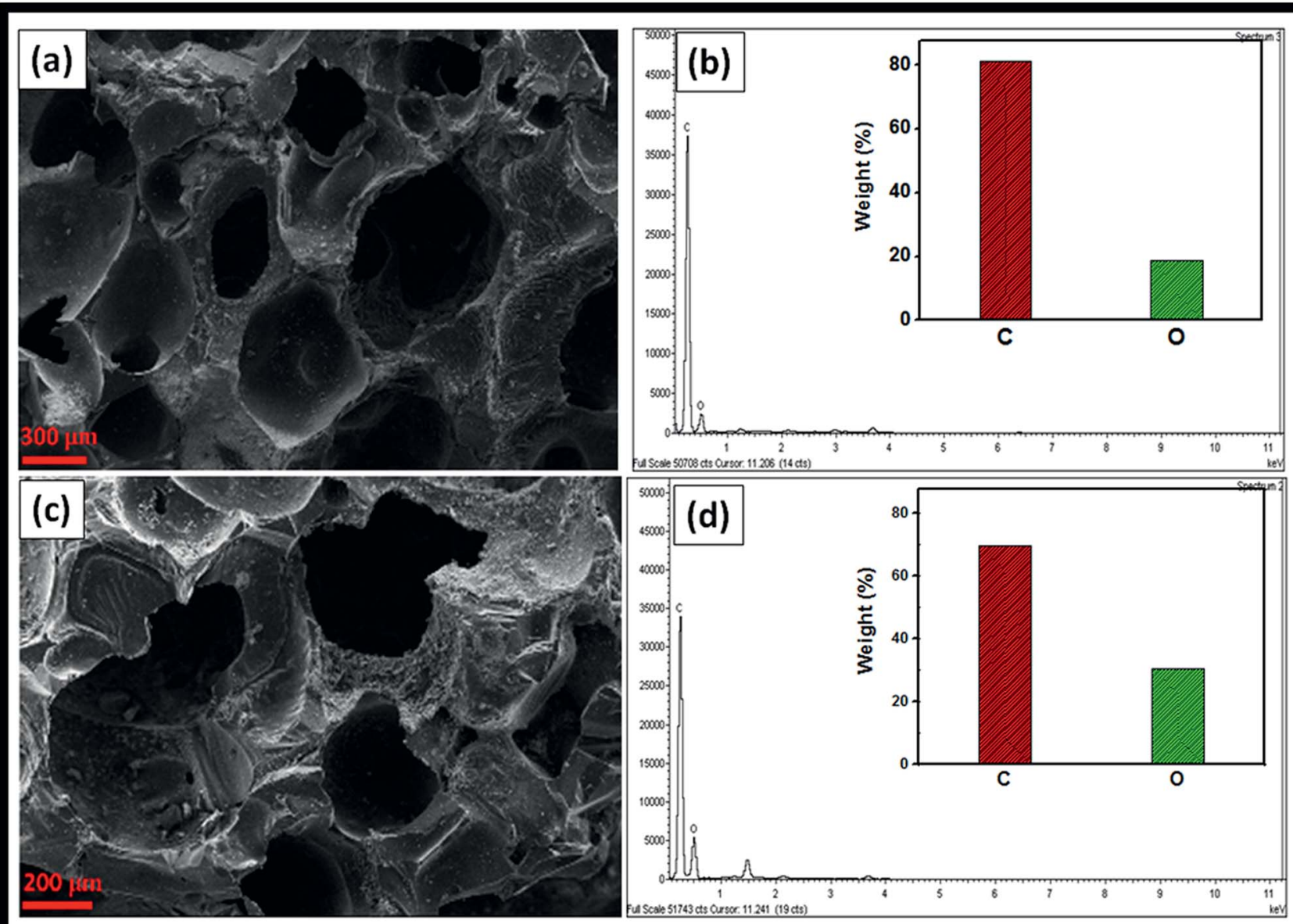

Fig. 10 SEM and EDX of used carbon foam (a) and (b) after treated with EDTA, (c) and (d) after treated with $\mathrm{HNO}_{3}$. 


$$
\begin{aligned}
\mathrm{H}_{2} \mathrm{AsO}_{4}{ }^{-}-\mathrm{CFoam}+ & \text { EDTA } \rightarrow \\
& \text { As-EDTA }+ \text { CFoam }+\mathrm{H}_{2} \mathrm{O}
\end{aligned}
$$

Furthermore, the EDX data of carbon foam shows that when the carbon foam is treated by $\mathrm{HNO}_{3}$, the oxygen content is increased to $30.4 \%$ as compare to carbon foam treated by EDTA, the increase in oxygen content is due the oxidation of carbon foam by $\mathrm{HNO}_{3}$ since $\mathrm{HNO}_{3}$ act as strong oxidising agent. Further, after removal of As(v), the carbon foam was treated with $\mathrm{HNO}_{3}$ and thoroughly washed with de-ionised water followed by drying at $105{ }^{\circ} \mathrm{C}$, the same material was used in second cycle at optimized condition. In the second cycle, $83.2 \%$ of arsenic gets adsorbed. In the same way the carbon foam was used after treated with $\mathrm{HNO}_{3}$ for third, fourth and fifth cycle having arsenic adsorption 60.1, 37.5 and $23.2 \%$ respectively. Furthermore, as carbon foam treated with $\mathrm{HNO}_{3}$ up to five times, the \% of arsenic removal decreased this is due to the decreasing of active sites on the surface of carbon foam.

\section{Conclusions}

In the present study, we report a cost effective method to synthesize novel 3D lightweight carbon foam from phenolic resin using PU template method. The SEM-EDAX, FTIR, XRD and XPS results indicating the adsorption of As(v) over the surface of carbon foam. The arsenic accumulated on the surface of carbon foam and water was purified upto safe potability limits of WHO and USEPA. The adsorption process followed Langmuir isotherm model suggesting monolayer adsorption. At optimized condition the maximum adsorption capacity of carbon foam for As(v) was found to be $38.4 \mu \mathrm{g} \mathrm{g}^{-1}$ in the $\mathrm{pH}$ range 4-5. Moreover carbon foam is nontoxic, easy to fabricate, affordable and insoluble in water. Raw material for fabrication of carbon foam is easily available everywhere. There is no requirement of any costly equipment for fabrication of carbon foam and filtration unit to separate carbon foam from water after adsorption process. Such material can be safely used in remote areas where there is scarcity of power supply. Therefore, from the practical point of view, the proposed carbon foam should be promising adsorbent for the removal of $\mathrm{As}(\mathrm{v})$ from drinking water.

\section{Acknowledgements}

Authors are highly grateful to Director, CSIR-NPL, for his kind permission to publish the results. The authors are also grateful to Dr Shailesh Kumar for FTIR studies and Dr R. P. Pant for XRD studies. Authors are also thankful to Mr Jai Tawale and Mr K. N. Sood for SEM characterization. The authors Pinki Rani Agrawal and Himani Uppal would like to thanks CSIR and UGC for JRF fellowship, respectively.

\section{References}

1 Y. Zhang, M. Yang and X. Huang, Chemosphere, 2003, 51, 945-952.
2 L. Keith and W. Telliard, Environ. Sci. Technol., 1979, 13, 416423.

3 S. V. Mohan, P. Nithila and S. J. Reddy, J. Environ. Sci. Health, Part A: Environ. Sci. Eng. Toxic Hazard. Subst. Control, 1996, 31, 283-289.

4 E. Levy, US Pat., 5,133,871, 1992.

5 R. Stone, Science, 2008, 321, 184-185.

6 Y.-L. Ren, H.-Y. Wu, M.-M. Lu, Y.-J. Chen, C.-L. Zhu, P. Gao, M.-S. Cao, C.-Y. Li and Q.-Y. Ouyang, ACS Appl. Mater. Interfaces, 2012, 4, 6436-6442.

7 T. Wang, L. Zhang, H. Wang, W. Yang, Y. Fu, W. Zhou, W. Yu, K. Xiang, Z. Su and S. Dai, ACS Appl. Mater. Interfaces, 2013, 5, 12449-12459.

8 S. Yamamura, J. Bartram, M. Csanady, H. G. Gorchev and A. Redekopp, Arsenic, Water, and Health: The State of the Art, ed. H. Hashizume and S. Yamamura, World Health Organisation, 2003.

9 I. Ali, V. K. Gupta, T. A. Khan and M. Asim, Int. J. Electrochem. Sci., 2012, 7, 1898-1907.

10 K. A. Graeme and C. V. Pollack, The Journal of emergency medicine, 1998, 16, 171-177.

11 E. Fogarassy, I. Galambos, E. Bekassy-Molnar and G. Vatai, Desalination, 2009, 240, 270-273.

12 N. Balasubramanian, T. Kojima, C. A. Basha and C. Srinivasakannan, J. Hazard. Mater., 2009, 167, 966-969.

13 K. Vaaramaa and J. Lehto, Desalination, 2003, 155, 157-170.

14 B. V. Tangahu, S. R. Sheikh Abdullah, H. Basri, M. Idris, N. Anuar and M. Mukhlisin, Int. J. Chem. Eng., 2011, 2011, 31.

15 K. Mozafarian, S. S. Madaeni and M. Khoshnodie, Water Wastewater, 2007, 17, 22-28.

16 V. Chandra, J. Park, Y. Chun, J. W. Lee, I.-C. Hwang and K. S. Kim, ACS Nano, 2010, 4, 3979-3986.

17 D. Mohan and C. U. Pittman, J. Hazard. Mater., 2007, 142, 153.

18 M. Elizalde-González, J. Mattusch, W.-D. Einicke and R. Wennrich, Chem. Eng. J., 2001, 81, 187-195.

19 Z. Liu, F.-S. Zhang and R. Sasai, Chem. Eng. J., 2010, 160, 5762.

20 O. Thirunavukkarasu, T. Viraraghavan and K. Subramanian, Water, Air, Soil Pollut., 2003, 142, 95-111.

21 J. A. Wilkie and J. G. Hering, Colloids Surf., A, 1996, 107, 97110.

22 W. Zhang, P. Singh, E. Paling and S. Delides, Miner. Eng., 2004, 17, 517-524.

23 G. T. Schmidt, N. Vlasova, D. Zuzaan, M. Kersten and B. Daus, J. Colloid Interface Sci., 2008, 317, 228-234.

24 F. Di Natale, A. Erto, A. Lancia and D. Musmarra, Water Res., 2008, 42, 2007-2016.

25 A. K. Gupta, D. Deva, A. Sharma and N. Verma, Ind. Eng. Chem. Res., 2010, 49, 7074-7084.

26 V. K. Upadhyayula, S. Deng, M. C. Mitchell and G. B. Smith, Sci. Total Environ., 2009, 408, 1-13.

27 K. Lü, G. Zhao and X. Wang, Chin. Sci. Bull., 2012, 57, 12231234.

28 H. Liu, K. Zuo and C. D. Vecitis, Environ. Sci. Technol., 2014, 48, 13871-13879. 
29 S. Vadahanambi, S.-H. Lee, W.-J. Kim and I.-K. Oh, Environ. Sci. Technol., 2013, 47, 10510-10517.

30 S Addo Ntim and S. Mitra, J. Chem. Eng. Data, 2011, 56, 20772083.

31 N. Mahanta and J. P. Chen, J. Mater. Chem. A, 2013, 1, 86368644.

32 X. Chen, K. F. Lam, Q. Zhang, B. Pan, M. Arruebo and K. L. Yeung, J. Phys. Chem. C, 2009, 113, 9804-9813.

33 Z. Wu and D. Zhao, Chem. Commun., 2011, 47, 3332-3338.

34 D. M. Burke, M. A. Morris and J. D. Holmes, Sep. Purif. Technol., 2013, 104, 150-159.

35 C.-G. Lee, J.-W. Jeon, M.-J. Hwang, K.-H. Ahn, C. Park, J.-W. Choi and S.-H. Lee, Chemosphere, 2015, 130, 59-65.

36 A. Yadav, R. Kumar, G. Bhatia and G. Verma, Carbon, 2011, 49, 3622-3630.

37 R. Kumar, A. P. Singh, M. Chand, R. P. Pant, R. K. Kotnala, S. K. Dhawan, R. B. Mathur and S. R. Dhakate, $R S C A d v$, 2014, 4, 23476-23484.
38 R. Kumar, S. R. Dhakate, T. Gupta, P. Saini, B. P. Singh and R. B. Mathur, J. Mater. Chem. A, 2013, 1, 5727-5735.

39 S. R. Dhakate, R. Kumar, R. B. Mathur and P. Saini, US Pat., 20,150,305,211, 2015.

40 N. Fiol and I. Villaescusa, Environ. Chem. Lett., 2009, 7, 7984.

41 N. Singh, A. Sarkar, R. Ramchandran and K. Lal, Asian J. Chem., 2003, 15, 1327-1330.

42 S. Zhang, X.-y. Li and J. P. Chen, Carbon, 2010, 48, 60-67.

43 S. Zhang, X.-y. Li and J. P. Chen, J. Colloid Interface Sci., 2010, 343, 232-238.

44 K. Wu, R. Liu, T. Li, H. Liu, J. Peng and J. Qu, Chem. Eng. J., 2013, 226, 393-401.

45 C. Karthika and M. Sekar, Res. J. Environ. Sci., 2012, 1, 34-41. 46 I. Langmuir, J. Am. Chem. Soc., 1918, 40, 1361-1403.

47 K. R. Hall, L. C. Eagleton, A. Acrivos and T. Vermeulen, Ind. Eng. Chem. Fundam., 1966, 5, 212-223. 